\title{
CATALYTIC THERMAL DECOMPOSITION OF POLYETHYLENE BY PYROLYSIS GAS CHROMATOGRAPHY
}

\author{
JAN NISAR* MUKHTIAR ALI, IFTIKHAR AHMAD AWAN \\ National Centre of Excellence in Physical Chemistry, University of Peshawar, \\ Peshawar-25120, Pakistan. \\ (Received: April 14, 2010 - Accepted: May 16, 2011)
}

\begin{abstract}
An experimental study of the thermal decomposition of polyethylene in an inert atmosphere has been carried out in the temperature range $300-800^{\circ} \mathrm{C}$ using Shimadzu PYR-2A pyrolyzer for heating the sample. The method allows the accurate control and measurement of the pyrolysis temperature. The production of hydrocarbons and the corresponding monomers of these polymeric systems were monitored. The effects of variation of temperature, sample size, pyrolysis atmosphere, residence time and catalyst on the distribution of these products were studied. As the carrier gas rapidly swept the primary products from the hot zone into the chromatographic column, so the secondary decomposition is largely eliminated and the pyrolysis products give accurate information about the nature, composition and structure of the pyrolysis material.
\end{abstract}

Keywords: Polyethylene; Catalytic thermal degradation; Pyrolysis gas chromatography.

\section{INTRODUCTION}

Polyethylene is the simplest and very frequently used polymer. Plastics based on polyethylene are present in large amount in domestic and industrial waste and can cause severe pollution problems. Its efficient use has an emergent importance these years due to the bigger demand for resource recycling and environmental safety ${ }^{1}$. The decomposition of polyethylene is of interest from different points of view, i.e. evolution of detrimental substances during fires or waste burning, recovering of chemical raw materials from plastic refuses and designing of recycling processes ${ }^{2}$. Many investigators have studied the pyrolysis of polyethylene $e^{3-6}$. In most studies, standard thermogravimetric analyzer (TGA) equipment was used for the measurements. In this study our focus is on the thermal decomposition of polyethylene using the technique of pyrolysis gas chromatography. The procedure involves, the thermal decomposition of polymer over the temperature range $300-800{ }^{\circ} \mathrm{C}$ using Shimadzu PYR-2A pyrolyzer. The volatile fragments produced as result of decomposition are passed through a gas chromatograph with suitable column for separation, identification and quantitation. The peaks corresponding to the major products in pyrograms are easily identified and are the characteristics of the material being pyrolysed. The yield and composition of pyrolysis products depends upon the nature of polymeric material, temperature of pyrolysis, residence time of volatile products in hot zone, sample size, pyrolysis atmosphere and the catalyst used.

\section{EXPERIMENTAL}

\subsection{Materials}

Low-density polyethylene (density $0.915 \mathrm{~g} / \mathrm{cm}^{3}$ and melting point $115^{\circ} \mathrm{C}$ ) was obtained commercially (Aldrich Chemical Company). Polymer wastes samples were obtained from "Twin Star Plastic Packages, Hayatabad, Peshawar, and khyber pakhtunkhwa., PAKISTAN". The catalysts used were alumina (basic), alumina (neutral), silica gel and zeolite. The polymer and catalyst blending was carried out mechanically. The catalyst concentration was $10 \%(\mathrm{w} / \mathrm{w})$. The standards used were of Philips Petroleum Company.

\subsection{Pyrolysis-Gas Chromatography system}

The pyrolyzer used for polymer pyrolysis was PYR-2A microfurnace consisting of main heater, pyrolysis chamber and operational rod. The temperature of the furnace was controlled by temperature control unit Model PYR-2A No. 20177U. The accuracy of the furnace temperature was between \pm 1 over the temperature range studied. The temperature was measured with a thermocouple, with which the platinum boat is attached. The furnace temperature was recorded on Shimadzu R112 bench type automatic balancing recorder. The full scale of the recorder indicates $1000^{\circ} \mathrm{C}$. The products were analyzed by gas chromatography using Shimadzu GC 7AG gas chromatograph with a flame ionization detector. Analyses were carried out using Squalene wall coated open tubular $(30 \times 0.25 \mathrm{~mm})$ column. Typical chromatographic conditions were, column oven temperature $70^{\circ} \mathrm{C}$, pyrolysis temperature $560^{\circ} \mathrm{C}$, carrier gas nitrogen with a flow rate of $50 \mathrm{~mL} / \mathrm{min}$, air pressure $0.5 \mathrm{Kg} / \mathrm{cm}^{2}$, hydrogen pressure $1 \mathrm{Kg} / \mathrm{cm}^{2}$, injection port temperature $150^{\circ} \mathrm{C}$. The area under the peaks was determined using the Spectra Physics Model Sp-4600 data jet integrator. The identification of products was done by comparison of the retention times of the peaks of standards with those of unknown.

\section{RESULTS AND DISCUSSIONS}

\subsection{Effect of pyrolysis Temperature}

Thermal decomposition of Low Density Polyethylene was carried out over the temperature range $500-800^{\circ} \mathrm{C}$ in nitrogen atmosphere. Precisely weighed $1 \mathrm{mg}$ polymer sample was used for each pyrolysis run. Nitrogen flow rate through the reactor was $50 \mathrm{~mL} / \mathrm{min}$, which corresponds to 0.609 second residence time. The interface between the pyrolyzer and Gas Chromatographic injection port was kept at $250^{\circ} \mathrm{C}$, which allowed only the volatile products to reach the chromatographic column. The observed volatiles during pyrolysis were identified as ethylene, propylene, isobutylene, 1-hexene and heptane. These volatiles products are formed as a result of scission of C-C bonds ${ }^{7,8}$. The effect of temperature on the \%yield of these products is reported in Figure 1. From the figure it is obvious that the yield of ethylene and propylene increases with increase in temperature, while the yield of 1-hexene decreases with rise in temperature. The yield of isobutylene increases with temperature and reaches a maximum around $560^{\circ} \mathrm{C}$ and then decreases above this temperature.

The increase in the yields of ethylene, propylene and isobutylene at higher temperatures $\left(\geq 560^{\circ} \mathrm{C}\right)$ can be explained on the basis of beta scission of primary radicals, which increases, by the rise in temperature. In other words due to the rapid scission of the polymer with increase in temperature, the yield of these hydrocarbons increases. The amount of isobutylene decreases as the temperature increases above $550^{\circ} \mathrm{C}$, which is due to decrease in unsaturated groups, which are responsible for the formation of this hydrocarbon. At lower temperatures $\left(\leq 560^{\circ} \mathrm{C}\right)$ there is less beta scission as compared to the transfer of free radical down the chain by backbiting to abstract a hydrogen atom and form secondary free radical, which undergoes beta scission to form more amounts of 1-hexene and haptane. 


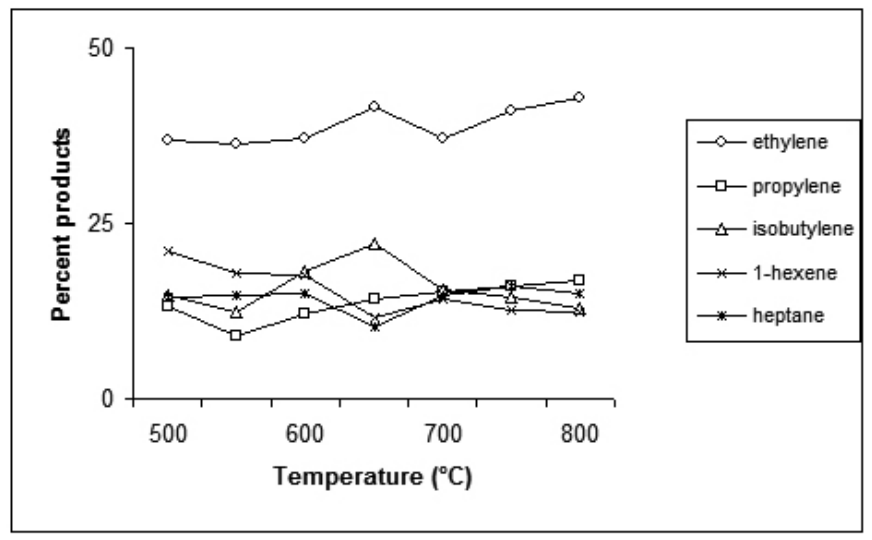

Fig. 1 Product yield as function of temperature from pyrolysis of polyethylene.

\subsection{Effect of Sample size}

The sample-size dependence study was carried out in the range of 1-10 mg sample of polyethylene at $560^{\circ} \mathrm{C}$. The results of this study are presented in Figure 2. It is observed from the results that the change in sample size in this range has no effect on the yields of major pyrolysis products within experimental errors. Therefore, in order to obtain more reproducible results in working with solid or powder samples, it is advisable to use samples of $1 \mathrm{mg}$ or more, unless special limitations are imposed.

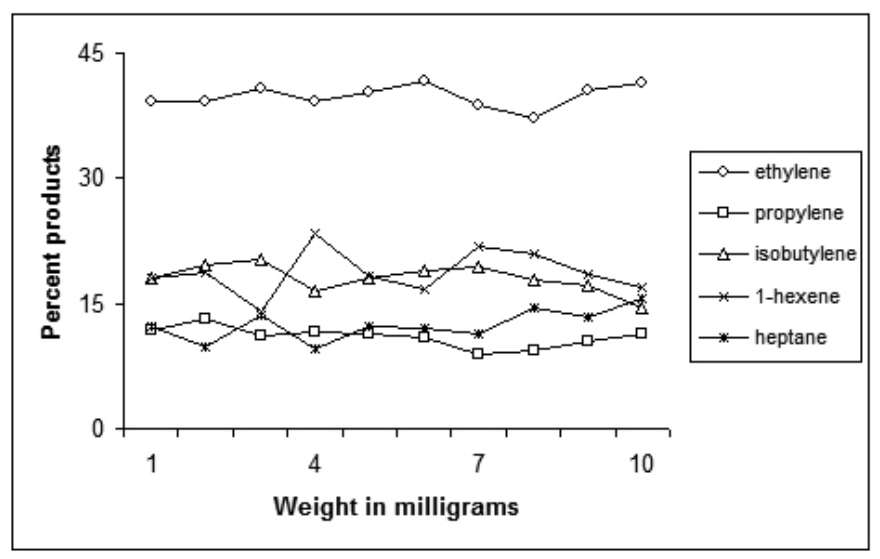

Fig. 2 Product yield as function of sample size from pyrolysis of polyethylene at $560^{\circ} \mathrm{C}$.

\subsection{Effect of Pyrolysis atmosphere}

In order to observe the effect of pyrolysis atmosphere on the nature and yields of the volatile products, the pyrolysis of polyethylene was carried out in nitrogen and helium atmosphere. The results are given in Table-1. It can be seen from the results that no significant changes in the nature and yields were found when the carrier gas was changed from nitrogen to helium. This is consistent with the work reported by Ristau, and Vanderborgh'. Wiley and Verraga ${ }^{10}$ in similar work reported that pyrolysis atmosphere has no effect on yields of the products resulted from the degradation of polyethylene.
Table 1 Dependence of products yield on atmosphere for the pyrolysis of polyethylene at $560{ }^{\circ} \mathrm{C}$.

\begin{tabular}{llllll}
\hline \multirow{2}{*}{ Atmosphere } & \multicolumn{5}{c}{ Percent Products } \\
\cline { 2 - 6 } & ethylene & propylene & isobutylene & 1-hexene & heptane \\
\hline Nitrogen & 33.35 & 11.69 & 18.08 & 23.48 & 13.40 \\
Helium & 34.92 & 13.71 & 14.43 & 23.80 & 10.63 \\
\hline
\end{tabular}

\subsection{Effect of catalyst}

To investigate the effect of catalyst on the amount of pyrolysis products, polyethylene alone and mixed with alumina (basic), alumina (neutral), silica gel and zeolite catalysts $\left(10 \%\right.$ by w/w), was degraded at $560^{\circ} \mathrm{C}$. The results are presented in Table-2. A general view of these results give an idea that an increase in the yields of these hydrocarbons is observed due to the presence of these additives in the sample of polyethylene. This is consistent with the reported literature ${ }^{11}$. Fernandes et al. ${ }^{12}$ studied the thermal decomposition of high-density polyethylene in the presence of silicoaluminophosphate as catalyst and concluded that thermal decomposition of polyethylene can be enhanced in the presence of this catalyst.

Table 2 Dependence of products yield on catalyst for the pyrolysis of polyethylene at $560{ }^{\circ} \mathrm{C}$.

\begin{tabular}{llllll}
\hline Catalyst & \multicolumn{5}{c}{ Percent Products } \\
\cline { 2 - 6 } & ethylene & propylene & isobutylene & 1-hexene & heptane \\
\hline None & 39.98 & 10.52 & 19.41 & 17.24 & 12.84 \\
$\mathrm{Al}_{2} \mathrm{O}_{3}$ (basic) & 29.02 & 15.53 & 18.20 & 22.57 & 15.61 \\
$\mathrm{Al}_{2} \mathrm{O}_{3}$ (neutral) & 25.67 & 15.21 & 17.59 & 24.09 & 17.43 \\
$\mathrm{SiO}_{2}$ & 26.39 & 11.48 & 17.70 & 22.97 & 13.40 \\
$\mathrm{Zeolite}^{2}$ & 23.19 & 11.39 & 17.39 & 28.40 & 17.04 \\
\hline
\end{tabular}

3.5 Effect of Residence Time

In order to check the effect of residence time on the yields of pyrolysis products, the polyethylene polymer samples were decomposed at $560^{\circ} \mathrm{C}$. The residence time of the volatile products in the hot zone was varied in the range $0.365-1.218$ seconds by changing the flow rate of carrier gas from $20-100 \mathrm{~mL} /$ $\mathrm{min}$. The results are shown in Figure 3. The results suggested that for residence time greater than 0.609 second (i.e. flow rate of carrier gas less than $50 \mathrm{~mL} /$ $\mathrm{min}$ ), the primary products were not immediately carried away from the hot zone and thus secondary reactions probably took place, increasing the yields of ethylene monomer and 1-hexene and correspondingly there is decrease in the yields of propylene, isobutylene and heptane. While the yields of all the major products did not show any appreciable change with the change in the residence time below 0.609 seconds (i.e. carrier gas flow rate between $50-100 \mathrm{~mL} / \mathrm{min}$ ). There is a great possibility of secondary reaction when the formed volatile products spend large time in the reactor as was observed by Barney Groten ${ }^{13}$. Therefore, in order to obtain more reproducible results, the residence time must be kept as low as possible in order to avoid the secondary decomposition.

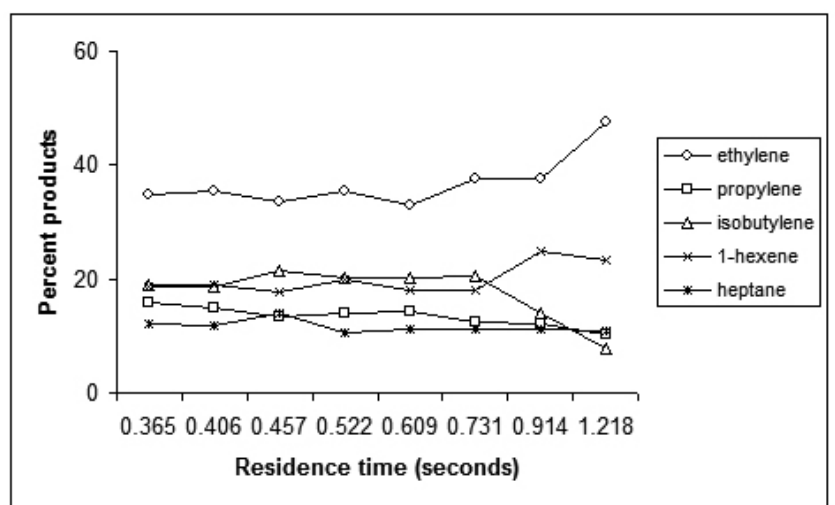

Fig. 3 Product yield as function of residence time from pyrolysis of polyethylene at $560^{\circ} \mathrm{C}$. 
3.6 Thermal decomposition of plastic wastes based on polyethylene Pyrolysis of industrial plastic packages based on low and high density polyethylene was studied at $560^{\circ} \mathrm{C}$. The results are reported in Table-3. As can be seen from the results there is no difference in the distribution of the volatile products obtained from the polymer wastes and standard polymer. However, the yield of monomer ethylene is about $7 \%$ less than the standard polymer. This study shows that locally available shopping packages after its use can be converted in to useful chemicals materials by pyrolysis.

Table 3 Comparison of products yields from the pyrolysis of polyethylene waste (shopping packages) with standard polymer at $560{ }^{\circ} \mathrm{C}$.

\begin{tabular}{llllll}
\hline Sample origin & \multicolumn{5}{c}{ Percent Products } \\
\cline { 2 - 6 } & ethylene & propylene & isobutylene & 1-hexene & heptane \\
\hline${ }^{a}$ LDPE (standard) & 39.98 & 10.52 & 19.41 & 17.24 & 12.84 \\
a LDPE (waste) & 32.80 & 13.09 & 18.75 & 15.86 & 19.68 \\
bHDPE (waste) & 31.80 & 14.75 & 18.15 & 16.71 & 18.61 \\
\hline
\end{tabular}

${ }^{\mathrm{a}} \mathrm{LDPE}=$ low density polyethylene

${ }^{\mathrm{b}} \mathrm{HDPE}=$ high density polyethylene

\section{CONCLUSIONS}

A method has been developed using Shimadzu PYR-2A pyrolyzer for the characterization of industrially manufactured polyethylene. This method is rapid and requires only 45 minutes and $1 \mathrm{mg}$ of polymer sample for each analysis. The use of capillary gas chromatography allowed the separation, identification and quantitation of individual monomer and hydrocarbon products resulting from pyrolysis. Among the various experimental variables, the temperature and catalyst are the most important parameters in determining the pyrolysis behaviour and provides basic information for utilizing this polymer in commercial projects. The observed similarity in the distribution and yields of volatile products from standard polymers and plastic wastes based on polyethylene suggests that the pyrolysis over temperature range $500-800^{\circ} \mathrm{C}$ can be used to convert these plastic wastes into corresponding monomers and hydrocarbons.

\section{REFERENCES}

1. Z. Gao, I. Amasaki , M. Nakada, J. Anal. Appl. Pyrolysis . 67, 1, (2003).

2. H. Bockhorn, A. Hornung, U. Hornung, J. Anal. Appl. Pyrolysis. 50, 77, (1999).

3. R.W.J. Westerhout, J. Waanders, J.A.M. Kuipers, W.P.M. van Swaaij, Ind. Eng. Chem. Res. 36, 1955, (1997).

4. H. Bockhorn, A. Hornung, U. Hornung, D. Schawaller, J. Anal. Appl. Pyrolysis. 48, 93, (1999).

5. C.-H. Wu, C.Y. Chang, J.L. Hor, S.M. Shih, L.W. Chen, F.W. Chang, Waste Manage. 13, 221, (1993).

6. M. Mucha, J. Polym. Sci. Symp. 57, 25, (1976).

7. K. Murata, Y. Hirano, Y. Sakata, M. Azhar Uddin, J. Anal. Appl. Pyrolysis $65,71,(2002)$.

8. M. Paboo, B. C. Levin, Fire Mater. 11, 55,(1987).

9. W. T. Ristau, N.E. Vanderborgh, Anal. Chem. 43, 702, (1971).

10. R. H. Wiley, P. Veeravagu, J. Phy. Chem. 72, 2417, (1968).

11. V. J. Fernandes Jr., A.S. Araujo, G.J.T. Fernandes, Stud. Surf. Sci. Catal. 105, 941, (1997).

12. G. J.T. Fernandes, V.J. Fernandes Jr., A.S. Araujo, Catal. Today. 75, 233(2002).

13. B. Groten, Anal. Chem. 36, 1206, (1964). 